\title{
Physicochemical Properties of 1-Methoxyethyl-3-Methylimidazolium Glycine
}

\author{
WEI Jie, DONG Hexin, CHEN Xia, YANG Yuxuan, FANG Dawei ${ }^{*}$, GUAN Wei ${ }^{*}$, YANG Jiazhen \\ Institute of Rare and Scattered Elements, College of Chemistry, Liaoning University, Shenyang 110036, P. R. China.
}

\begin{abstract}
Because of the unique acid-base behavior of amino acids, we combined glycine as the anion with an ether group as the cation and prepared a novel ionic liquid (IL), 1-methoxyethyl-3-methylimidazolium glycine [MOEMIM][Gly]. The formation of this IL was confirmed by ${ }^{1} \mathrm{H}-\mathrm{NMR},{ }^{13} \mathrm{C}-\mathrm{NMR}$, differential scanning calorimetry (DSC) and thermogravimetry (TG) analyses. The density, $\rho$, and surface tension, $\gamma$, of the ILs were measured in the temperature range from $298.15 \mathrm{~K}$ to $338.15 \mathrm{~K}$ at intervals of $5 \mathrm{~K}$ using the standard addition method, because the strong hydrogen bonds between the IL [MOEMIM][Gly]

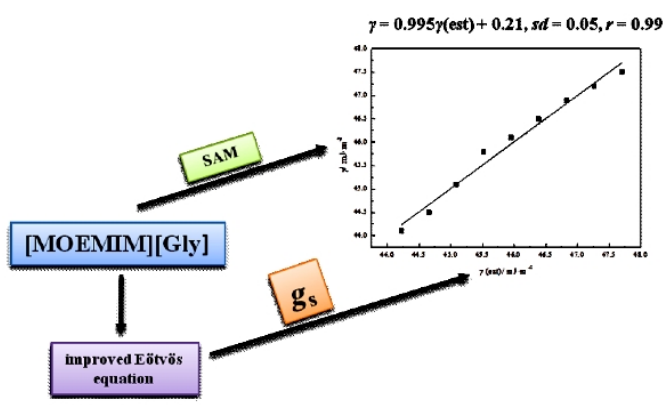
and trace amounts of water made it, extremely difficult to remove water by convention methods. The calculated molar volume, $V_{\mathrm{m}}$, of [MOEMIM][Gly] increased with increasing temperature. The thermal expansion coefficient, $\alpha$, was also obtained based on the density values. In terms of the molar surface Gibbs free energy, $g_{\mathrm{s}}$ for [MOEMIM][Gly], the traditional Eötvös equation is improved so that it has physical significance, that is, the intercept $C_{0}$ represents molar surface enthalpy, $h$, which is a temperature-independent constant and the slop $C_{1}=$ $-\left(\partial g_{s} / \partial T\right)_{\mathrm{p}}$ is molar surface entropy, $s$, it shows that modified Eötvös equation is not only an empirical equation, but also a strict thermodynamic one. In addition, by a combination of $g_{\mathrm{s}}$ and the modified Eötvös equation, the surface tension values of [MOEMIM][Gly] were estimated and compared with the experimental values; both sets of data were in good accordance with each other.
\end{abstract}

Key Words: 1-Methoxyethyl-3-methy limidazolium glycine; Density; Surface tension; Molar surface Gibbs free energy

\section{1-甲氧基乙基-3-甲基咪唑甘氨酸离子液体的物理化学性质的研究}

魏杰, 董贺新, 陈霞, 杨宇轩, 房大维 ${ }^{*}$, 关伟 ${ }^{*}$, 杨家振

辽宁大学化学院稀散元素研究院, 沈阳 110036

摘要: 由于氨基酸基的独特性质, 我们以甘氨酸作为阴离子, 醚基咪唑基团作为阳离子合成了一种新型离子液体 1-甲氧 乙基-3-甲基咪夾甘氨酸[MOEMIM][Gly], 并经过核磁共振氢谱、核磁共振碳谱和差示扫描量热进行表征。由于离子液体 和水之间形成氢键导致传统的方法不能去除水的影响, 所以在实验测定中, 选用标准加入法在温度范围为 298.15-338.15 $\mathrm{K}$, 每隔 $5 \mathrm{~K}$ 测定离子液体 [MOEMIM][GIy]的密度和表面张力。利用密度数据, 计算得到离子液体 [MOEMIM][GIy] 的摩尔 体积, 并且摩尔体积随着温度的升高而增加, 同时得到了热膨胀系数。根据离子液体[MOEMIM][GIy]的摩尔表面 Gibbs 自由能, 改进了传统的 Eötvös 经验方程, 使得方程具有更明确的物理意义, 即截距 $C_{0}$ 代表摩尔表面焓, 它是一个与温

Received: December 25, 2017; Revised: January 9, 2018; Accepted: January 9, 2018; Published online: January 11, 2018

${ }^{*}$ Corresponding authors. Email: davidfine@163.com; Tel: +86-24-62202006 (F.D.). Email:guanweiy@sina.com (G.W.).

The project was supported by the National Natural Science Foundation of China (21673107, 21373005, 21703090).

国家自然科学基金 $(21673107,21373005,21703090)$ 资助项目

(C) Editorial office of Acta Physico-Chimica Sinica 
度无关的常数, 斜率则为摩尔表面熵, 这表明改进的 Eötvös 方程不仅是一个经验方程, 而且还是严格的热力学方程。 另外, 结合摩尔表面 Gibbs 自由能和改进的 Eötvös 方程, 估算了离子液体的[MOEMIM][GIy]的表面张力, 并与实验值 进行比较, 发现两者很好的一致。

关键词：1-甲氧乙基-3-甲基咪唑甘氨酸；密度；表面张力；摩尔表面Gibbs自由能 中图分类号: 0642

\section{Introduction}

As a new-generation green solvent, ionic liquids (ILs) have attracted considerable attention from industry and academic community. In particular, amino acid ionic liquids are a special class of ionic liquids due to their unique acid-base behavior, biological significance, and applications in different fields such as templates in synthetic chemistry, stabilizers for biological macromolecules ${ }^{1}$, etc. The physicochemical properties of these ionic liquids can easily be altered by making the different combinations of amino acids as anion along with possible cation modification which makes the ionic liquids more suitable to understand the different kinds of molecular and ionic interactions with sufficient depth so that they can provide fruitful information for a molecular level understanding of more complicated biological processes. And in recent years, there has been a developing trend in the literature toward the ether-functionalized ILs on the carbohydrate dissolution ${ }^{2-5}$, enzymatic acylation ${ }^{6}$, extraction ${ }^{7,8}, \mathrm{CO}_{2}$ capture ${ }^{9}$, gas separation ${ }^{10}$, and organic reactions ${ }^{11-14}$ and it is also found that incorporating an ether group can have an influence on the viscosity of ILs ${ }^{15-18}$, which is drawn the attention from more and more people.

Hence, we combined glycine as anion with ether group in the cation and prepared a novel ionic liquids, and the physicochemical properties have been further investigated by the semi-empirical methods, which can not be regarded as accurate physicochemical data, although it is to be commended because it provides valuable insight into the origins of the behavior of the materials. In this paper, the new results are reported as follows: A novel ionic liquid 1-methoxyethyl-3-methy limidazolium glycine [MOEMIM] [Gly] is prepared and confirmed by ${ }^{1} \mathrm{H}-\mathrm{NMR}$ spectrum, ${ }^{13} \mathrm{C}$-NMR spectrum, DSC and TG. The determination of densities, $\rho$, and surface tensions, $\gamma$, of the ILs at $T=$ 298.15-338.15 K with an interval of $5 \mathrm{~K}$ using standard addition method (SAM); (3) The volume properties of IL [MOEMIM][Gly] are discussed; (4) The molar surface Gibbs free energy for [MOEMIM][Gly] is calculated in different temperatures, and in terms of the molar surface Gibbs free energy, $g_{s}$, the modified Eötvös equation is applied to [MOEMIM][Gly]; (5) Combined the molar surface Gibbs free energy with modified Eötvös equation, the surface tension is estimated.

\section{Experimental}

\subsection{Chemicals}

Deionized water with a conductance of $(0.8-1.2) \times 10^{-4}$ $\mathrm{S} \cdot \mathrm{m}^{-1}$ was used in experiments. 1-Methylimidazole (AR-grade) was purchased from ACROS and vacuum-distilled prior to use. Glycine, 1-bromo-2-methoxyethane, diethyl ether, acetonitrile, methanol and anion-exchange resin (type 717) were purchased from Shanghai Chemical Reagent Co. Ltd. and glycine was recrystallized twice and was dried under reduced pressure, anion-exchange resin (type 717) was activated by the regular method before use. The purity and some related information of the chemicals are listed in Table S1.

\subsection{Preparation of [MOEMIM][GIy]}

[MOEMIM][Gly] were prepared by the neutralization method as described in the literatures ${ }^{19,20}$. Under the protection of argon, a solution of 1-methylimidazole (1 eq) and 1-bromo-2-methoxyethane (1.1 eq) in round-bottom flask is stirred at $25{ }^{\circ} \mathrm{C}$ for $18 \mathrm{~h}$, then diethyl ether $(80 \mathrm{~mL})$ was added to the solution and continued to react for $36 \mathrm{~h}$ to obtain white solid product [MOEMIM][Br], which was washed in diethyl ether at least 3 times. Next, by use of activated anion-exchange resin, the aqueous [MOEMIM] $[\mathrm{OH}]$ was prepared from [MOEMIM][Br]. Then aqueous [MOEMIM][OH] was added dropwise to a slightly excess glycine aqueous solution, and then it was stirred for $50 \mathrm{~h}$. The scheme shows the synthetic route (see Scheme 1). Then water was evaporated under reduced pressure. To this reaction mixture was added the mixed solvent acetonitrile/methanol (volumetric ratio $=9 / 1$ ), and it was stirred befittingly. The mixture was then filtered to remove excess glycine. Filtrate was evaporated under reduced pressure to remove solvents. The product of [MOEMIM][Gly] was dried in vacuo for 2 days at $80{ }^{\circ} \mathrm{C}$. Structures of the resulting

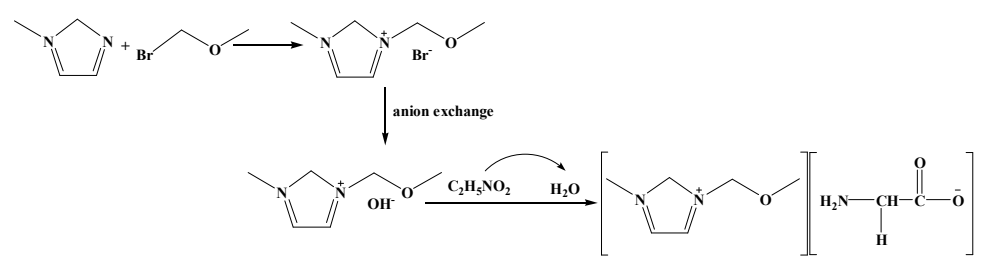

Scheme 1 Synthesis of functionalized IL [MOEMIM][Gly]. 
[MOEMIM][Gly] were confirmed by ${ }^{1} \mathrm{H}-\mathrm{NMR}$ spectrum, ${ }^{13} \mathrm{C}-\mathrm{NMR}$ spectrum, DSC and TG (see Figs. $\mathrm{S} 1-\mathrm{S} 4$ in Supporting Information).

Element analysis show the purity of the synthesized ionic liquids is more than 0.99 .

Mass fraction of water in [MOEMIM][Gly] determined by a Karl Fischer moisture titrator (ZSD-2 type) is $380 \times 10^{-6}$. Ion selective electrode measurements reveal that the mass fraction of halogen $\left(\mathrm{Br}^{-}\right)$is less than $210 \times 10^{-6}$.

\subsection{Determination of density and surface tension for [MOEMIM][GIy]}

It is extremely difficult to remove any water in [MOEMIM][Gly] by conventional methods because the ionic liquid can strongly form hydrogen bonds with water, so the SAM ${ }^{21-23}$ is applied in these measurements in order to eliminate the effect of water. According to SAM, a series of samples of [MOEMIM][Gly] with various mass fraction of water were prepared.

An Anton Paar DMA 4500 oscillating U-tube densitometer is used to measure the density of a series of samples. The temperature in the cell is regulated to $\pm 0.03 \mathrm{~K}$ with solid state thermostat. Before measurement, the apparatus was calibrated once a day with dry air and double-distilled freshly degassed water. Using the calibrated densitometer, the densities of the degassing water are measured at $T=298.15-338.15 \mathrm{~K}$ with interval $5 \mathrm{~K}$ and was in good agreement with the literature 24 within experimental error. Then the densities of all samples are measured by the densitometer in the same temperature range.

Using the tensiometer of the forced bubble method (DPAW type produced by Sang Li Electronic Co.), the surface tension of water is measured at $T=298.15-338.15 \mathrm{~K}$ and was in good agreement with the literature ${ }^{24}$ within experimental error. Then the values of surface tension of the samples are measured by using the same method in the same temperature range.

\section{Results and discussion}

\subsection{The values of density, $\rho$, and surface tension, $y$, of IL [MOEMIM][GIy]}

The values of density and surface tension for the samples of [MOEMIM][Gly] containing various contents of water are listed in Tables 1 and 2, respectively. Each value in the tables is the average of triplicate measurements. According to the SAM, the values of density and surface tension of the samples are plotted against the mass fraction of water, $w_{2}$ ( $w_{2}$ is the mass percentage) respectively, so that a series of good straight lines are obtained (see Figs. 1 and 2). The values of correlation coefficient, $r$, for all linear regressions are larger than 0.998 and all values of standard deviation, SD, are within standard

Table 1 At $T=(298.15-338.15) \mathrm{K}^{\mathrm{a}}$ and pressure $p=0.1 \mathrm{MPa}^{\mathrm{b}}$, density values for [MOEMIM][Gly], $\rho$, mass fraction of water, $w_{2}{ }^{\mathrm{c}}$ in [MOEMIM][Gly].

\begin{tabular}{|c|c|c|c|c|c|c|c|c|}
\hline \multirow{2}{*}{$T / \mathrm{K}$} & \multicolumn{6}{|c|}{$\rho /\left(\mathrm{g} \cdot \mathrm{cm}^{-3}\right)$} & \multirow{2}{*}{$r$} & \multirow{2}{*}{$10^{6} \mathrm{SD}$} \\
\hline & $10^{3} w_{2}=6.31$ & $10^{3} w_{2}=7.84$ & $10^{3} w_{2}=9.36$ & $10^{3} w_{2}=10.5$ & $10^{3} w_{2}=11.9$ & 0 & & \\
\hline 298.15 & 1.17691 & 1.17696 & 1.17702 & 1.17707 & 1.17712 & $1.17667 \pm 0.00006$ & 0.999 & 4.37 \\
\hline 303.15 & 1.17361 & 1.17365 & 1.17370 & 1.17374 & 1.17379 & $1.17341 \pm 0.00006$ & 0.998 & 5.04 \\
\hline 308.15 & 1.17029 & 1.17034 & 1.17039 & 1.17043 & 1.17047 & $1.17009 \pm 0.00006$ & 0.999 & 2.32 \\
\hline 313.15 & 1.16704 & 1.16710 & 1.16714 & 1.16719 & 1.16723 & $1.16683 \pm 0.00006$ & 0.998 & 5.96 \\
\hline 318.15 & 1.16362 & 1.16367 & 1.16371 & 1.16375 & 1.16380 & $1.16342 \pm 0.00006$ & 0.999 & 4.37 \\
\hline 323.15 & 1.16058 & 1.16063 & 1.16067 & 1.16071 & 1.16074 & $1.16040 \pm 0.00006$ & 0.998 & 4.96 \\
\hline 328.15 & 1.15734 & 1.15740 & 1.15745 & 1.15750 & 1.15754 & $1.15711 \pm 0.00006$ & 0.999 & 5.01 \\
\hline 333.15 & 1.15411 & 1.15415 & 1.15419 & 1.15423 & 1.15427 & $1.15393 \pm 0.00006$ & 0.999 & 3.77 \\
\hline 338.15 & 1.15089 & 1.15094 & 1.15099 & 1.15103 & 1.15107 & $1.15069 \pm 0.00006$ & 0.999 & 2.32 \\
\hline
\end{tabular}

Standard uncertainties $\left(0.68\right.$ level of confidence): ${ }^{\mathrm{a}} u(T)= \pm 0.03 \mathrm{~K},{ }^{\mathrm{b}} u(p)= \pm 0.002 \mathrm{MPa},{ }^{\mathrm{c}} u\left(w_{2}\right)=0.00010$ for water mass fraction.

Table 2 At $^{\text {a }} T=(298.15-338.15)$ K and pressure ${ }^{\mathrm{b}} p=0.1 \mathrm{MPa}$, surface tension values for [MOEMIM] [Gly], $\gamma$ mass fraction of water, ${ }^{\mathrm{c}} \boldsymbol{w}_{2}$ in [MOEMIM][Gly].

\begin{tabular}{|c|c|c|c|c|c|c|c|c|}
\hline \multirow{2}{*}{$T / \mathrm{K}$} & \multicolumn{6}{|c|}{$\gamma /\left(\mathrm{mJ} \cdot \mathrm{m}^{-2}\right)$} & \multirow{2}{*}{$r$} & \multirow{2}{*}{$10^{2} \mathrm{SD}$} \\
\hline & $10^{3} w_{2}=6.51$ & $10^{3} w_{2}=8.04$ & $10^{3} w_{2}=9.44$ & $10^{3} w_{2}=10.93$ & $10^{3} w_{2}=12.5$ & 0 & & \\
\hline 298.15 & 50.7 & 51.4 & 52.2 & 52.9 & 53.6 & $47.5 \pm 0.4$ & 0.999 & 5.45 \\
\hline 303.15 & 50.3 & 51.0 & 51.7 & 52.4 & 53.1 & $47.2 \pm 0.3$ & 0.999 & 2.31 \\
\hline 308.15 & 49.9 & 50.5 & 51.2 & 51.9 & 52.6 & $46.9 \pm 0.4$ & 0.999 & 4.29 \\
\hline 313.15 & 49.5 & 50.1 & 50.8 & 51.5 & 52.2 & $46.5 \pm 0.4$ & 0.999 & 4.29 \\
\hline 318.15 & 49.0 & 49.7 & 50.4 & 51.0 & 51.7 & $46.1 \pm 0.4$ & 0.999 & 3.89 \\
\hline 323.15 & 48.6 & 49.3 & 49.9 & 50.6 & 51.2 & $45.8 \pm 0.4$ & 0.999 & 3.78 \\
\hline 328.15 & 48.1 & 48.8 & 49.5 & 50.2 & 50.8 & $45.1 \pm 0.4$ & 0.999 & 5.58 \\
\hline 333.15 & 47.6 & 48.3 & 49.0 & 49.7 & 50.4 & $44.5 \pm 0.3$ & 0.999 & 2.31 \\
\hline 338.15 & 47.2 & 47.9 & 48.6 & 49.3 & 50.0 & $44.1 \pm 0.3$ & 0.999 & 2.31 \\
\hline
\end{tabular}

Standard uncertainties ( 0.68 level of confidence): ${ }^{\mathrm{a}} u(T)= \pm 0.03 \mathrm{~K},{ }^{\mathrm{b}} u(p)= \pm 0.002 \mathrm{MPa},{ }^{\mathrm{c}} u\left(w_{2}\right)=0.00010$ for water mass fraction. 


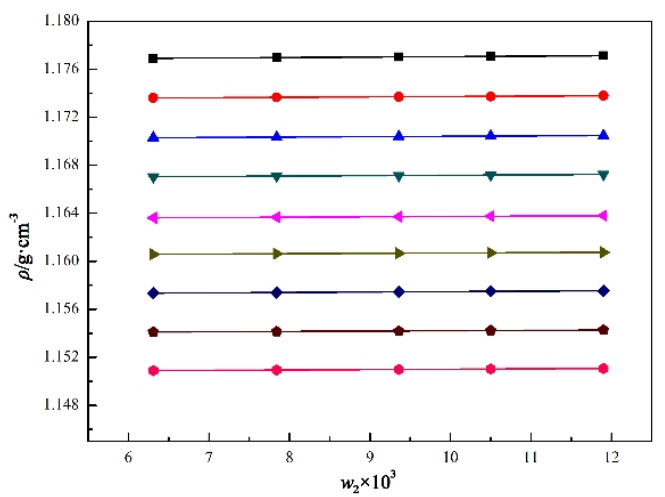

Fig. 1 Plot density, $\rho$, $v s$ mass fraction of water, $w_{2}$ in [MOEMIM][Gly] in the temperature range of 298.15-338.15 K.

- $298.15 \mathrm{~K}: \rho=1.17667+3.8225 \times 10^{-5} w_{2}, \mathrm{SD}=4.37 \times 10^{-6}, r=0.999$.

- $303.15 \mathrm{~K}: \rho=1.17341+3.2434 \times 10^{-5} w_{2}, \mathrm{SD}=5.04 \times 10^{-6}, r=0.998$

$\Delta 308.15 \mathrm{~K}: \rho=1.17009+3.2414 \times 10^{-5} w_{2}, \mathrm{SD}=2.32 \times 10^{-6}, r=0.999$.

$\nabla 313.15 \mathrm{~K}: \rho=1.16683+3.3917 \times 10^{-5} w_{2}, \mathrm{SD}=5.96 \times 10^{-6}, r=0.998$

$\triangleleft 318.15 \mathrm{~K}: \rho=1.16342+3.1735 \times 10^{-5} w_{2}, \mathrm{SD}=4.37 \times 10^{-6}, r=0.999$.

- $323.15 \mathrm{~K}: \rho=1.16040+2.8905 \times 10^{-5} w_{2}, \mathrm{SD}=4.96 \times 10^{-6}, r=0.998$

- $328.15 \mathrm{~K}: \rho=1.15711+3.6111 \times 10^{-5} w_{2}, \mathrm{SD}=5.01 \times 10^{-6}, r=0.999$.

- $333.15 \mathrm{~K}: \rho=1.15393+2.8825 \times 10^{-5} w_{2}, \mathrm{SD}=3.77 \times 10^{-6}, r=0.999$.

- $338.15 \mathrm{~K}: \rho=1.15069+3.2514 \times 10^{-5} w_{2}, \mathrm{SD}=2.32 \times 10^{-6}, r=0.999$.

uncertainty of the measurement. The intercepts of the straight lines are the values of density or surface tension of [MOEMIM][Gly] without water and can be viewed as experimental values, which are listed in the 7th column of Tables 1 and 2, respectively. From these data, it turned out that using the SAM is appropriate. Standard uncertainties $(0.68$ level of confidence) for temperature, pressure and water mass fraction are listed in the footnote of Tables 1 and 2, and the expanded uncertainties $U_{\mathrm{c}}(0.95$ level of confidence) for density and surface tension are also listed in the 7th column of Tables 1 and 2, respectively.

\subsection{Volumetric properties of [MOEMIM][Gly]}

According to the definition of molar volume, $V_{\mathrm{m}}$ :

$V_{\mathrm{m}}=M / \rho$

where $M$ is molar mass, $\rho$ is the density. From experimental values of density, the molar volume, $V_{\mathrm{m}}$ of [MOEMIM][Gly] at $T=(298.15-338.15) \mathrm{K}$ are calculated and the results are listed in Table 3. These results indicate that the values of $V_{\mathrm{m}}$ increase with the increasing of temperature.

In addition, according to definition of thermal expansion coefficient, $\alpha$ :

$$
\alpha \equiv\left(1 / V_{\mathrm{m}}\right)\left(\partial V_{\mathrm{m}} / \partial T\right)_{\mathrm{p}}=-(\partial \ln \rho / \partial T)_{\mathrm{p}}
$$

where $V_{\mathrm{m}}$ is molar volume. Plotting $\ln \rho v_{S} T$, the straight line was obtained (see Fig. 3), and the slope is the thermal expansion coefficient, that is $\alpha=5.58 \times 10^{-4} \mathrm{~K}^{-1}$ for [MOEMIM][Gly], which can be seen as experimental value of thermal expansion coefficient.

\subsection{The mole surface Gibbs free energy and the modified Eötvös equation}

For most of the liquids, the relationship between surface

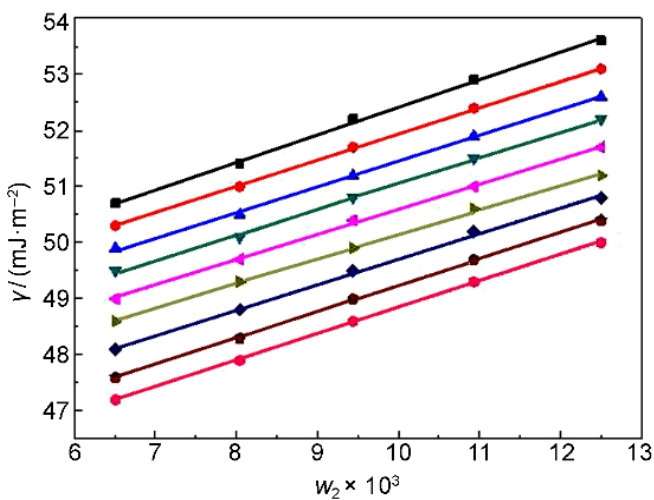

Fig. 2 Plot surface tension, $\gamma$, vs mass fraction of water, $w_{2}$ in [MOEMIM][Gly] in the temperature range 298.15-338.15 K.

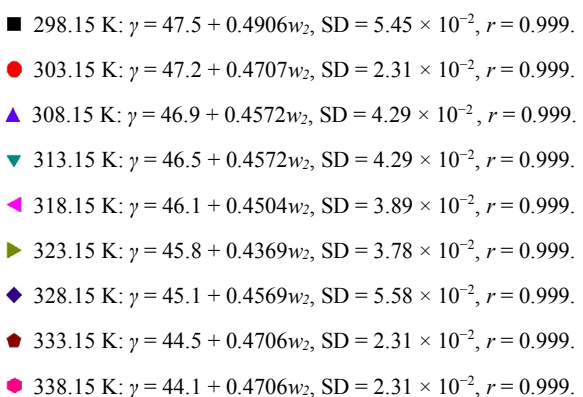

tension and the temperature is usually expressed as Eötvös equation 25 :

$$
\gamma V_{\mathrm{m}}^{2 / 3}=k_{\mathrm{E}}\left(T_{\mathrm{c}}-T\right)
$$

where $\gamma$ is surface tension, $V_{\mathrm{m}}$ is molar volume, $T_{\mathrm{c}}$ is critical temperature and $k_{\mathrm{E}}$, which is related to polarity of the liquid, is Eötvös constant. Although the traditional Eötvös empirical equation can well explain the relationship between surface tension and temperature, in which the physical significance of $\gamma V_{\mathrm{m}}^{2 / 3}$ is not clear and the dimension $\left(\mathrm{J} \cdot \mathrm{mol}^{-2 / 3}\right)$ is not convenient to use. So we used a new thermodynamic function, the molar surface Gibbs free energy, $g_{\mathrm{s}}$, derived by Tong et al. ${ }^{26,27}$ and Guan et al. ${ }^{28}$ and it has been applied to the properties of ionic liquids for the first time.

The definition of $g_{\mathrm{s}}$ is:

$$
g_{\mathrm{s}}=\gamma V_{\mathrm{m}}^{2 / 3} N^{1 / 3}
$$

where $\gamma$ is surface tension, $V_{\mathrm{m}}$ is molar volume and $N$ is Avogadro constant. The values of $g_{\mathrm{s}}$ calculated from Eq. (4) are listed in the fourth column of Table 3. Plotting $g_{\mathrm{s}}$ versus $T$, a straight line is obtained (see Fig. 4), the correlation coefficient of the linear regression is 0.99 .

The relationship between the molar surface Gibbs free energy, $g_{\mathrm{s}}$, and temperature, $T$ can be expressed in the following improved empirical equation:

$$
g_{\mathrm{s}}=C_{0}-C_{1} T
$$

where $C_{0}$ and $C_{1}$ are empirical parameters, $C_{1}=19.17$ $\mathrm{J} \cdot \mathrm{K}^{-1} \cdot \mathrm{mol}^{-1}, C_{0}=18.70 \mathrm{~kJ} \cdot \mathrm{mol}^{-1}$ with relative coefficient $r=$ 0.99 and $s d=0.0012$ for [MOEMIM][Gly]. That is to say, based on the molar surface Gibbs free energy, $g_{\mathrm{s}}$, the Eötvös empirical equation is improved.

\subsection{The estimation of surface tension of [MOEMIM][GIy]}




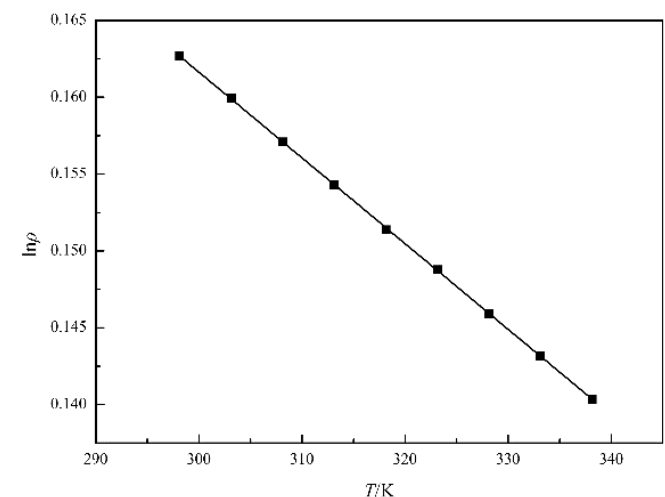

Fig. 3 Plot of $\ln \rho$ vs $T$ for [MOEMIM][Gly].

$\ln \rho=-5.58 \times 10^{-4} T+0.33, \mathrm{SD}=5.4 \times 10^{-2}, r=0.9999$

Table 3 The values of $V_{\mathrm{m}}, \gamma V_{\mathrm{m}}^{2 / 3}, g_{\mathrm{s}}$ and $\gamma(\mathrm{est})$ for [MOEMIM][Gly].

\begin{tabular}{ccccc}
\hline$T / \mathrm{K}$ & $10^{4} V_{\mathrm{m}} /\left(\mathrm{m}^{3} \cdot \mathrm{mol}^{-1}\right)$ & $10^{4} \gamma V_{\mathrm{m}}^{2 / 3} /\left(\mathrm{J} \cdot \mathrm{mol}^{-2 / 3}\right)$ & $g_{\mathrm{s}} /\left(\mathrm{kJ} \cdot \mathrm{mol}^{-1}\right)$ & $\gamma(\mathrm{est}) /\left(\mathrm{mJ} \cdot \mathrm{m}^{-2}\right)$ \\
\hline 298.15 & 1.830 & 1.531 & 12.93 & 47.7 \\
303.15 & 1.835 & 1.524 & 12.87 & 47.3 \\
308.15 & 1.840 & 1.517 & 12.81 & 46.8 \\
313.15 & 1.846 & 1.507 & 12.73 & 46.4 \\
318.15 & 1.851 & 1.497 & 12.64 & 45.9 \\
323.15 & 1.856 & 1.490 & 12.58 & 45.5 \\
328.15 & 1.861 & 1.470 & 12.41 & 45.1 \\
333.15 & 1.866 & 1.453 & 12.27 & 44.7 \\
338.15 & 1.871 & 1.443 & 12.18 & 44.2 \\
\hline
\end{tabular}

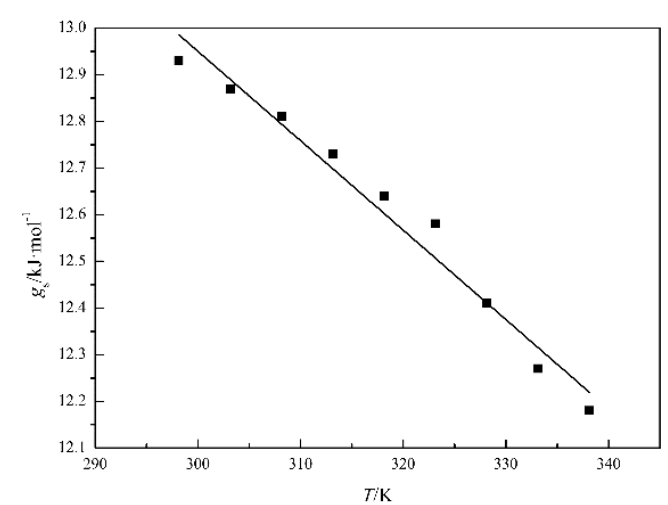

Fig. 4 Plot the molar surface Gibbs free energy, $g_{\mathrm{s}}$, vs temperature, $T$ for [MOEMIM] [Gly] in the temperature range of 298.15-338.15 K.

$$
g_{\mathrm{s}}=18.70-0.01917 T, \mathrm{SD}=0.0012, \quad r=0.99 .
$$

From the modified Eötvös equation Eq. (5), it is noticed that $C_{0}$ and $C_{1}$ have clear physical significance, $C_{0}$ represents molar surface enthalpy, $h$, which is a temperature-independent constant and $C_{1}=-\left(\partial g_{\mathrm{s}} / \partial T\right)_{\mathrm{p}}$ is molar surface entropy, $s$. Since molar surface enthalpy is independent with temperature, molar surface heat capacity $c_{\mathrm{p}}=0$ which implies that the process from the inside to the surface of the liquid is an isocoulombic one 29 (an isocoulombic reaction is the one in which the number and charge of charged species are identical on both sides of the reaction. Reaction of this type tends to have near-zero heat capacity change and thus has constant enthalpy with increasing temperature). Combined Eq. (4) with Eq. (5), the values of

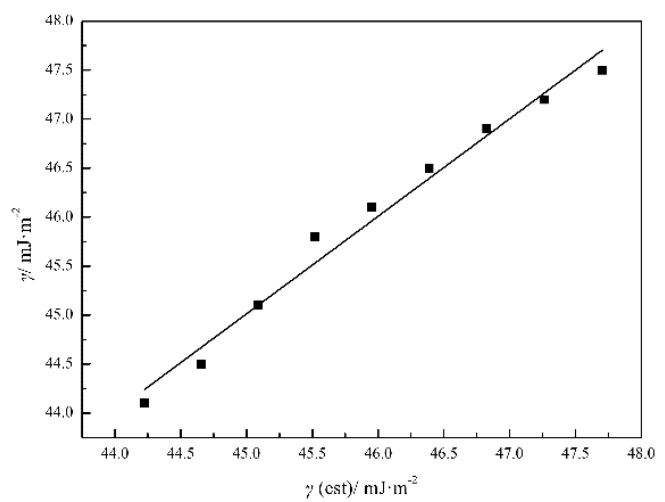

Fig. 5 Plot the experimental surface tension values, $\gamma v s$ the estimated ones, $\gamma$ (est) for [MOEMIM][Gly].

$$
\gamma=0.995 \gamma(\text { est })+0.21, \mathrm{SD}=0.05, r=0.99 \text {. }
$$

surface tension are estimated, and are listed in Table 3. Plotting the experimental surface tension values, $\gamma v s$ the estimated ones, $\gamma$ (est), a good straight line was showed (see Fig. 5). The results reveal that the values of $\gamma$ and $\gamma($ est $)$ are almost consistent (the intercept $=0.2$ approximately 0 and the slope $=0.995$ approximately 1). These facts show that new Eötvös equation is not only an empirical equation, but also a strict thermodynamic one.

\section{Conclusions}

A functional ionic liquids [MOEMIM][Gly] is prepared for the first time and confirmed by ${ }^{1} \mathrm{H}-\mathrm{NMR}$ spectrum, ${ }^{13} \mathrm{C}-\mathrm{NMR}$ spectrum and DSC. By using SAM, density and surface tension of the ILs at $T=298.15-338.15 \mathrm{~K}$ with an interval of $5 \mathrm{~K}$ have been determined, and molar volume, $V_{\mathrm{m}}$ are calculated, and these results indicate that the values of $V_{\mathrm{m}}$ increase with the increasing of temperature. In addition, thermal expansion coefficient, $\alpha=5.579 \times 10^{-4} \mathrm{~K}^{-1}$ for [MOEMIM][Gly] is also obtained, which can be seen as experimental value of thermal expansion coefficient. Then, we used a new thermodynamic function, the molar surface Gibbs free energy, $g_{\mathrm{s}}$ to improve the Eötvös equation, and the modified one has clear physical significance, $C_{0}$ represents molar surface enthalpy, $h$, which is a temperature-independent constant and $C_{1}=-\left(\partial g_{\mathrm{s}} / \partial T\right)_{\mathrm{p}}$ is molar surface entropy, $s$. Since molar surface enthalpy is independent with temperature, molar surface heat capacity $c_{\mathrm{p}}=0$ which implies that the process from the inside to the surface of the liquid is an isocoulombic one. In addition, the surface tension of [MOEMIM][Gly] is estimated based on the $g_{\mathrm{s}}$ and the modified Eötvös equation. The results reveal that the values of $\gamma$ and $\gamma$ (est) are almost consistent. These turn out that improved Eötvös equation is not only an empirical one, but also a strict thermodynamic one.

Supporting Information: available free of charge via the internet at http://www.whxb.pku.edu.cn. 


\section{References}

(1) Beniwal, V.; Kumar, A. J. Phys. Chem. B 2017, 121, 11367. doi: $10.1021 /$ acs.jpcb. 7 b08240

(2) Kuhlmann, E.; Himmler, S.; Giebelhaus, H.; Wasserscheid, P. Green Chem. 2007, 9, 233. doi: 10.1039/B611974C

(3) Zhao, H.; Baker, G. A.; Song, Z.; Olubajo, O.; Crittle, T.; Peters, D. Green Chem. 2008, 10, 696. doi: 10.1039/B801489B

(4) Zhao, H.; Jones, C. L.; Cowins, J. V. Green Chem. 2009, 11, 1128. doi: 10.1039/B905388C

(5) Zhao, H.; Baker, G. A.; Cowins, J. V. Biotechnol. Prog. 2010, 26, 127. doi: 10.1002/btpr.331

(6) Galletti, P.; Moretti, F.; Samori, C.; Tagliavini, E. Green Chem. 2007, 9, 987. doi: 10.1039/B702031G

(7) Revelli, A. L.; Mutelet, F.; Jaubert, J. N.; Garcia-Martinez, M.; Sprunger, L. M.; AcreeJr, W. E.; Baker, G. A. J. Chem. Eng. Data 2010, 55, 2434. doi: 10.1021/je900838a

(8) Mutelet, F.; Revelli, A. L.; Jaubert, J. N.; Sprunger, L. M.; Acree, W. E.; Baker, G. A. J. Chem. Eng. Data 2010, 55, 234. doi: $10.1021 /$ je9003178

(9) Yang, Z. Z.; Zhao, Y. N.; He, L. N. RSC Adv. 2011, 1, 545. doi: 10.1039/C1RA00307K

(10) Ginderen, P. V.; Herrebout, W. A.; van der Veken, B. J. J. Phys. Chem. A 2003, 107, 5391. doi: 10.1021/jp034553i

(11) Sasaki, K.; Matsumura, S.; Toshima, K. A. Tetrahedron Lett. 2004, 45, 7043. doi: 10.1016/j.tetlet.2004.07.128

(12) Wang, L.; Zhang, Y. H.; Xie, C. S.; Wang, Y. G. 2005, 36, 1861. doi: $10.1055 / \mathrm{s}-2005-871566$

(13) Luo, C.; Zhang, Y.; Wang, Y. J. Mol. Catal. A: Chem. 2005, 229, 7. doi: 10.1016/j.molcata.2004.10.039

(14) Petrović, Z. D.; Marković, S.; Petrović, V. P.; Simijonović, D. J. Mol. Model. 2012, 18, 433. doi: 10.1007/s00894-011-1052-1

(15) Monteiro, M. J.; Camilo, F. F.; Ribeiro, M. C. C.; Torresi, R. M.
J. Phys. Chem. B. 2010, 114, 12488. doi: 10.1021/jp104419k

(16) Smith, G. D.; Borodin, O.; Li, L.; Kim, H.; Liu, Q.; Bara, J. E.; Gin, D. L.; Nobel, R. A. Phys. Chem. Chem. Phys. 2008, 10, 6301. doi: $10.1039 / \mathrm{B} 808303 \mathrm{G}$

(17) Fang, S.; Yang, L.; Wang, J.; Li, M.; Tachibana, K.; Kamijima, K. Electrochim. Acta 2009, 54, 4269. doi: 10.1016/j.electacta.2009.02.082

(18) Zheng, J. C.; Tong, X.; Lee, J. M. RSC Adv. 2012, 2, 10564. doi: 10.1039/C2RA21772D

(19) Tao, G. H.; He, L.; Liu, W. S.; Xu, L.; Xiong, W.; Wang, T.; Kou, Y. Green Chem. 2006, 8, 639. doi: 10.1039/B600813E

(20) Fukumoto, K.; Yoshizawa, M.; Ohno, H. J. Am. Chem. Soc. 2005, 127, 2398. doi: 10.1021/ja043451i

(21) Wei, J.; Chang, C.; Zhang, Y. Y.; Hou, S. Y.; Fang, D. W.; Guan, W. J. Chem. Thermodyn. 2015, 90, 310. doi: 10.1016/j.jct.2015.04.029

(22) Ma, X. X.; Wei, J.; Zhang, Q. B.; Tian, F.; Feng, Y. Y.; Guan, W. Ind. Eng. Chem. Res. 2013, 52, 9490. doi: 10.1021/ie401130d

(23) Fang, D. W.; Tong, J.; Guan, W.; Wang, H.; Yang, J. Z. J. Phys. Chem. B 2010, 114, 13808. doi: 10.1021/jp107452q

(24) Lide, D. R. Handbook of Chemistry and Physics, 82nd ed.; CRC Press: Boca Raton, FL, USA, 2001-2002.

(25) Adamson, A.W. Physical Chemistry of Surfaces; Wiley: New York, NY, USA, 1976.

(26) Tong, J.; Wang, L. F.; Liu, D. L.; Chen, T. F.; Tong, J.; Yang, J. Z. J. Chem. Thermodyn. 2016, 97, 221. doi: 10.1016/j.jct.2016.01.009

(27) Tong, J.; Yang, H. X.; Liu, R. J.; Li, C.; Xia, L. X.; Yang, J. Z. J. Phys. Chem. B 2014, 118, 12972. doi: 10.1021/jp509240w

(28) Wei, J.; Fan, B. H.; Pan, Y.; Xing, N. N.; Men, S. Q.; Tong, J.; Guan, W. 2016, 101, 278. doi: 10.1016/j.jct.2016.03.043

(29) Mountain, B. W.; Seward, T. M. Geochim. Cosmochim. Acta 2003, 67, 3005. doi: 10.1016/S0016-7037(03)00303-X 